\title{
Management of Non-Vitamin K Antagonist Oral Anticoagulants in the Perioperative Setting
}

\author{
Anne-Sophie Dincq, ${ }^{1}$ Sarah Lessire, ${ }^{1,2}$ Jonathan Douxfils, ${ }^{2}$ Jean-Michel Dogné, ${ }^{2}$ \\ Maximilien Gourdin, ${ }^{1}$ and François Mullier ${ }^{3}$ \\ ${ }^{1}$ Department of Anesthesiology, CHU Dinant Godinne UcL Namur, Namur Thrombosis and Hemostasis Center (NTHC), \\ Namur Research Institute of Life Sciences (NARILIS), 5530 Yvoir, Belgium \\ ${ }^{2}$ Department of Pharmacy, University of Namur, Namur Thrombosis and Hemostasis Center (NTHC), \\ Namur Research Institute of Life Sciences (NARILIS), 5000 Namur, Belgium \\ ${ }^{3}$ Haematology Laboratory, CHU Dinant Godinne UcL Namur, Namur Thrombosis and Hemostasis Center (NTHC), \\ Namur Research Institute of Life Sciences (NARILIS), 5530 Yvoir, Belgium \\ Correspondence should be addressed to Anne-Sophie Dincq; anne-sophie.dincq@uclouvain.be
}

Received 30 May 2014; Accepted 5 August 2014; Published 3 September 2014

Academic Editor: Helen Mani

Copyright ( 2014 Anne-Sophie Dincq et al. This is an open access article distributed under the Creative Commons Attribution License, which permits unrestricted use, distribution, and reproduction in any medium, provided the original work is properly cited.

\begin{abstract}
The field of oral anticoagulation has evolved with the arrival of non-vitamin $\mathrm{K}$ antagonist oral anticoagulants (NOACs) including an anti-IIa agent (dabigatran etexilate) and anti-Xa agents (rivaroxaban and apixaban). The main specificities of these drugs are predictable pharmacokinetics and pharmacodynamics but special attention should be paid in the elderly, in case of renal dysfunction and in case of emergency. In addition, their perioperative management is challenging, especially with the absence of specific antidotes. Effectively, periods of interruption before surgery or invasive procedures depend on half-life and keeping a permanent balance between bleeding and thromboembolic risks. In addition, few data regarding the link between plasma concentrations and their effects are provided. Routine laboratory tests are altered by NOACs and quantitative measurements are not widely performed. This paper provides a review on the management of NOACs in the perioperative setting, including the estimation of the bleeding and thrombotic risk, the periods of interruption, the indication of heparin bridging, the usefulness of laboratory tests before surgery or invasive procedure, and the time of resuming. Most data are based on expert's opinions.
\end{abstract}

\section{Introduction}

Three non-vitamin $\mathrm{K}$ antagonist oral anticoagulants (NOACs) [1] are already widely used in the clinical setting: rivaroxaban and apixaban, two direct factor $\mathrm{Xa}(\mathrm{FXa})$ inhibitors, and dabigatran etexilate (DE) - the prodrug of dabigatran, a direct thrombin inhibitor. Both of these drugs will progressively tend to replace vitamin $\mathrm{K}$ antagonists (VKAs) in most of their indications. NOACs indications vary among countries. They are licensed for long-term prevention of thromboembolic events in nonvalvular atrial fibrillation (NVAF), for thromboprophylaxis of venous thromboembolism (VTE) including deep venous thromboembolism (DVT) and pulmonary embolism (PE) after hip and knee arthroplasty, and for the treatment and secondary prophylaxis of
VTE. Rivaroxaban is also approved in Europe for secondary prevention of atherothrombotic events after acute coronary syndrome (ACS) with elevated cardiac biomarkers [2-7].

Advantages of NOACs include rapid onset and offset of action and relatively predictable anticoagulation effects [8]. In most patients, routine laboratory monitoring of the anticoagulant effect is not required but the assessment of the estimated renal clearance is necessary [9]. In some cases (e.g., emergencies, bleeding, overdose, and trauma), the anticoagulation status and the alteration of standard laboratory data must be known $[10,11]$. An increasing number of patients on long-term treatment with NOACs are encountered in the perioperative setting and it is essential for physicians to be aware of the pharmacological properties of these drugs. The management of those patients requires an involvement of 
all participating teams (general practitioners, surgeons, anesthesiologists, and other healthcare professionals involved in invasive procedures). Their cessation is indisputable in most elective procedure, but the risk between thrombosis and bleeding should be balanced [12]. In some settings, the therapeutic window is bridged by low molecular weight heparin (LMWH) or unfractionated heparin (UFH) to prevent thromboembolic risk $[13,14]$. No specific antidote is currently available in case of bleeding so clinicians have to deal with rescue treatments [15]. The optimal time for NOAC's resumption depends mainly on the postoperative risk of bleeding [16].

This paper aims at providing a review on the management of NOACs in the perioperative setting in accordance with the current literature. This includes the estimation of the bleeding and thrombotic risk of each patient, the period of NOAC's interruption before an invasive procedure, the conditions for heparin bridging during this interruption, the usefulness of common and specific laboratory tests to assess the remaining anticoagulant effect preoperatively, and the time of NOAC's resumption prerequisites for the perioperative management of NOACs. The literature search was performed in PubMed using the following keywords: perioperative, anticoagulant, dabigatran, rivaroxaban, and apixaban. Overall inclusion of papers was limited to studies published until May 30, 2014.

\section{Indications and Posology of NOACs}

Three molecules are currently available in the clinical setting: dabigatran etexilate (Pradaxa, Boehringer-Ingelheim Pharma $\mathrm{GmBH}$, Ingelheim am Rhein, Germany): $75 \mathrm{mg}, 110 \mathrm{mg}$, and $220 \mathrm{mg}$ capsules, rivaroxaban (Xarelto, Johnson and Johnson/Bayer HealthCare AG, Leverkusen, Germany): $2.5 \mathrm{mg}$, $10 \mathrm{mg}, 15 \mathrm{mg}$, and $20 \mathrm{mg}$ tablets, and apixaban (Eliquis, Bristol Myers Squibb/Pfizer, Bristol Myers Squibb House, Uxbridge, United Kingdom): $2.5 \mathrm{mg}$ and $5 \mathrm{mg}$ tablets.

Table 1 summarizes the approved indications by the Food and Drug Administration and the European Commission, the posology, and the dose adaptation of the different NOACs.

Table 2 summarizes the main studies leading to the approved indications of NOACs [17-27].

\section{Clinician Oriented Overview of Pharmacokinetic Properties of NOACs}

3.1. Dabigatran Etexilate (Pradaxa, Boehringer-Ingelheim Pharma GmBH, Ingelheim am Rhein, Germany): $75 \mathrm{mg}$, $110 \mathrm{mg}$, and $220 \mathrm{mg}$ Capsules. Dabigatran etexilate is the prodrug of dabigatran, a selective and reversible oral direct thrombin inhibitor. The plasma peak after ingestion is at 1.53.0 hours and the plasma trough level is 11-14 hours after ingestion in healthy volunteers [28]. Bioavailability varies from 3 to $7 \%$ depending on the $\mathrm{pH}$ encountered in the microenvironment of the gastrointestinal tract. Dabigatran is $35 \%$ bound to plasma proteins, allowing theoretically its elimination by hemodialysis. Eighty percent of the drug is directly eliminated in the urine, explaining that, in the setting of renal insufficiency, the anticoagulant effect accumulates. Its elimination half-life rises to $18-24$ hours in patients with significantly impaired renal function compared to healthy elderly subjects [29]. Creatinine clearance ( $\mathrm{CrCl})$ estimation based on the Cockroft and Gault formula [30, 31] is recommended in elderly patients to calculate doses and avoid overmedication [9]. Twenty percent is conjugated as glucuronides by hepatic metabolism. Dabigatran etexilate is contraindicated in case of severe renal impairment $(\mathrm{CrCl}<30 \mathrm{~mL} / \mathrm{min})$ in Europe while a lower dose is proposed in North America for $\mathrm{CrCl}$ between 30 and $15 \mathrm{~mL} / \mathrm{min}$ [32]. Hepatic impairment or liver disease with expected impact on survival is also a contraindication $[33,34]$.

3.2. Rivaroxaban. Rivaroxaban is a selective and reversible oral direct FXa inhibitor. The plasma peak after ingestion is at 2-4 hours and the half-life elimination is 5-9 hours in healthy volunteers and 11-13 hours in the elderly [28]. Bioavailability is between 80 and $100 \%$ for $10 \mathrm{mg}$ and around $66 \%$ for 15 or $20 \mathrm{mg}$ under fasting conditions. Rivaroxaban is bound to plasma proteins in more than 90\%, making hemodialysis ineffective to eliminate this drug. About one-third (36\%) of the dose is eliminated by renal pathway as unchanged active drug, and the approximately remaining two-thirds of the dose is subject to metabolic degradation. Metabolites are eliminated equally via renal pathway and via hepatobiliary route in the feces [35]. Clearance is mildly influenced by renal function [36]. Rivaroxaban is not recommended in severe renal impairment $(\mathrm{ClCr}<15 \mathrm{~mL} / \mathrm{min})$ [32].

3.3. Apixaban. Apixaban is a selective and reversible oral direct FXa inhibitor. The plasma peak after ingestion is at 23 hours and the half-life elimination is $8-15$ hours in healthy volunteers [28]. Apixaban is $87 \%$ bound to plasma proteins. Bioavailability is around $50 \%$. Apixaban is eliminated via multiple pathways: predominantly via the fecal route $(56 \%)$ and $25-29 \%$ via renal excretion [37]. Apixaban is not recommended in severe renal impairment $(\mathrm{ClCr}<15 \mathrm{~mL} / \mathrm{min})$ [32].

Table 3 proposes an overview of the main pharmacokinetic properties of direct oral anticoagulants.

\section{Drugs Interactions}

Two mechanisms are mainly involved in NOACs' metabolism and elimination: the efflux operated by P-glycoprotein (Pgp) and the CYP450 isoform CYP3A4. Dabigatran etexilate is metabolized in dabigatran in the plasma and liver via CYP450-independent mechanisms [38], but DE acts as a substrate for P-gp. Therefore, strong inhibitors or inducers of P-gp may alter the absorption of DE [39]. Rivaroxaban and apixaban are metabolized by CYP3A4/5 and are both substrates for P-gp. Thus, drugs that strongly inhibit or induce CYP3A4 or P-gp or both influence the pharmacokinetic (PK) profile of these NOACs $[39,40]$.

\section{Perioperative Management of NOACs}

As illustrated in the RE-LY (randomized evaluation of longterm anticoagulation therapy) study [41], 25\% of the patients 


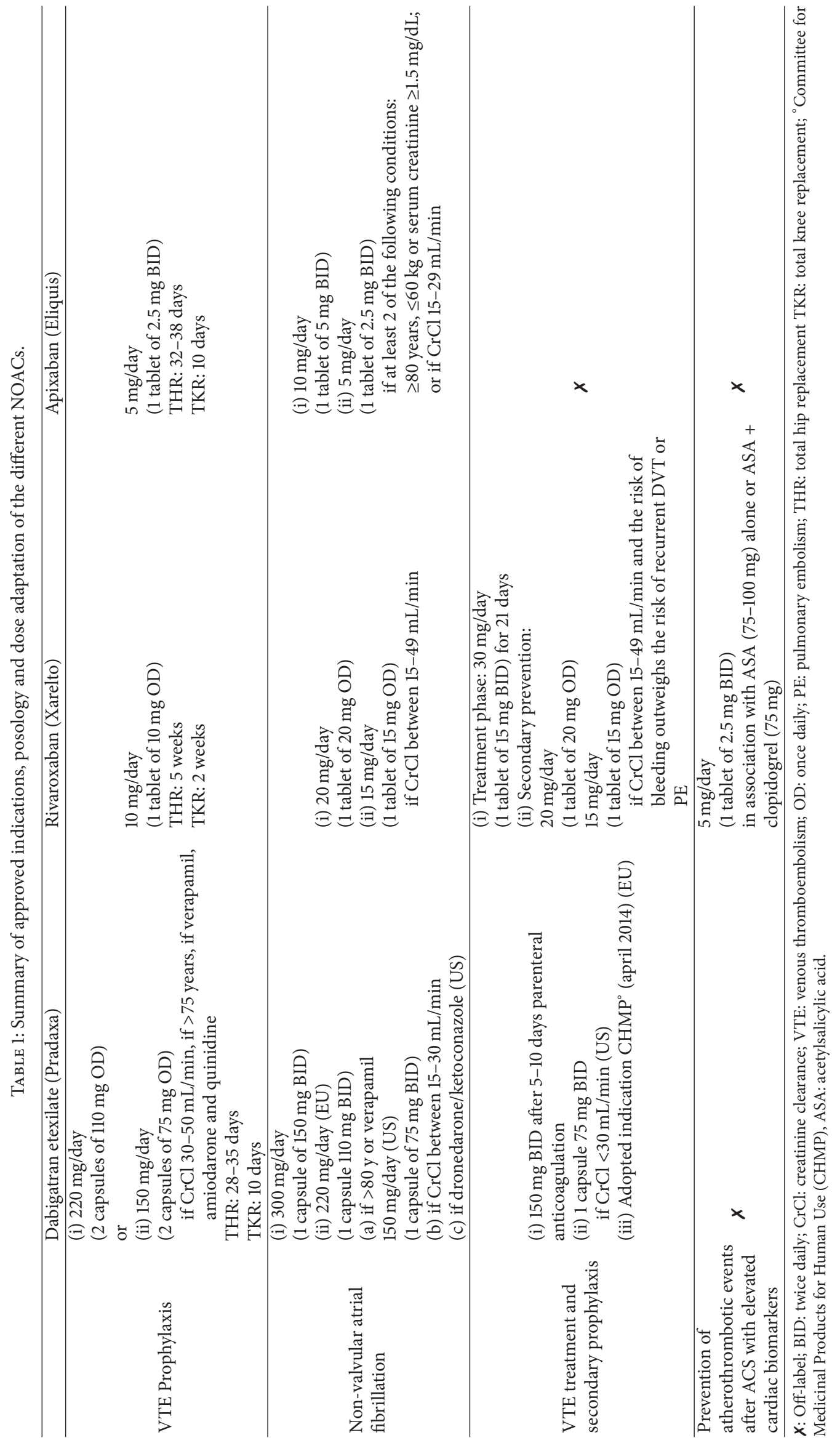




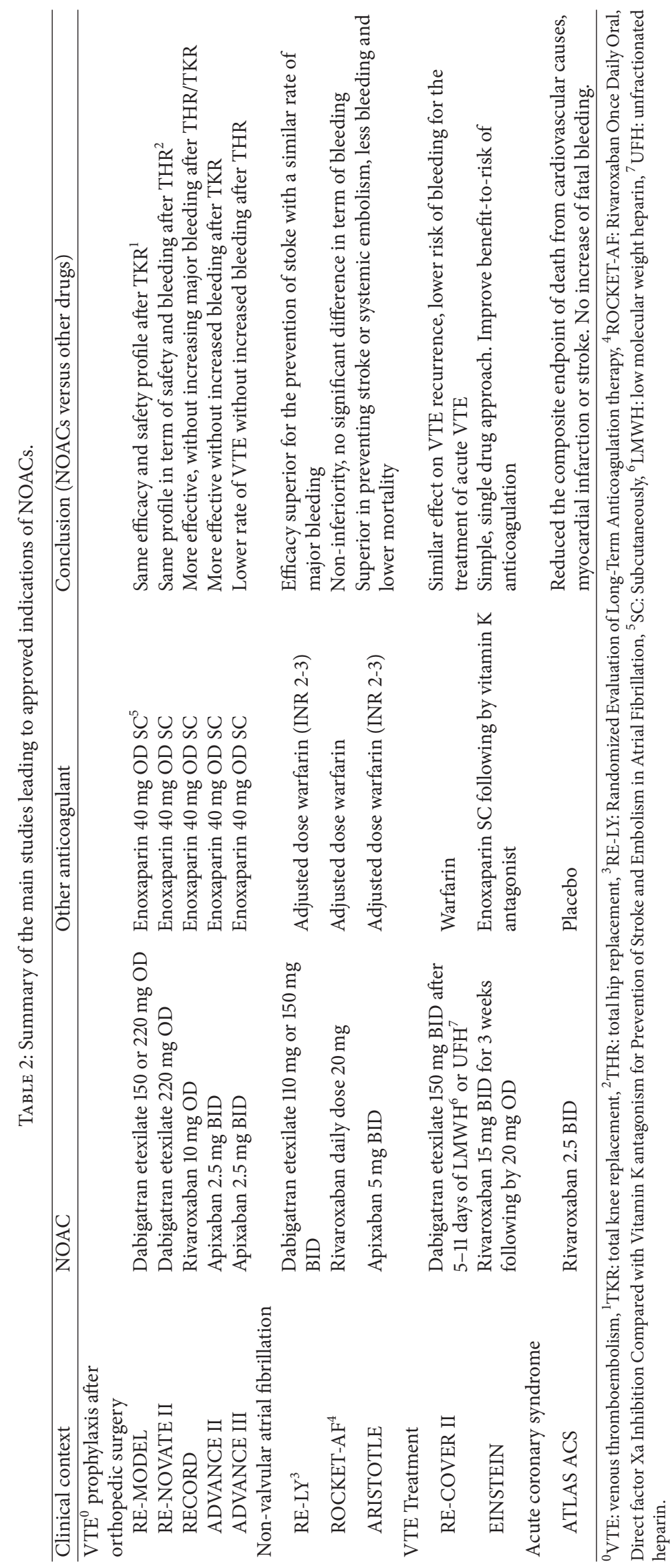


TABLE 3: Overview of main pharmacokinetic properties of NOACs.

\begin{tabular}{|c|c|c|c|}
\hline & Dabigatran etexilate & Rivaroxaban & Apixaban \\
\hline Plasma peak (hours) & $1.5-3.0$ & $2.0-4.0$ & $3.0-4.0$ \\
\hline Elimination half-life (hours) & $\begin{array}{l}\text { 11-14: healthy volunteers } \\
\text { 18-24: significantly impaired } \\
\text { renal function }\end{array}$ & $\begin{array}{l}\text { 5-9: healthy volunteers } \\
\text { 11-13: elderly }\end{array}$ & 8-15: healthy volunteers \\
\hline Protein binding (\%) & $35 \%$ & $>90 \%$ & $87 \%$ \\
\hline Elimination (\%) & $\begin{array}{c}80 \% \text { active renal } \\
20 \% \text { faecal }\end{array}$ & $\begin{array}{c}33 \% \text { non-active renal } \\
66 \% \text { metabolized: (metabolism: } \\
50 \% \text { renal and other half by } \\
\text { hepatobiliary route) }\end{array}$ & $\begin{array}{l}\text { Multiples pathways: } \\
25 \%-29 \% \text { renal } \\
56 \% \text { by faecal route }\end{array}$ \\
\hline Bioavailability & $\begin{array}{c}3-7 \% \\
\text { PH sensitive }\end{array}$ & $\begin{array}{c}\text { 80-100\% } 10 \mathrm{mg} \\
\text { 66\%: } 15-20 \text { mg under fasting } \\
\text { conditions }\end{array}$ & $\pm 50 \%$ \\
\hline
\end{tabular}

TABLE 4: $\mathrm{CHA}_{2} \mathrm{DS}_{2}$-VASc Score.

\begin{tabular}{lcc}
\hline Acronym & $\mathrm{CHA}_{2} \mathrm{DS}_{2}$-Vasc Score & Points \\
\hline $\mathrm{C}$ & Congestive heart failure & 1 \\
$\mathrm{H}$ & Hypertension & 1 \\
$\mathrm{~A}_{2}$ & Age $\geq 75$ years & 2 \\
$\mathrm{D}$ & Diabetes mellitus & 1 \\
$\mathrm{~S}_{2}$ & Stroke, transient attack, or thromboembolism & 2 \\
$\mathrm{~V}$ & Vascular disease (prior myocardial infarction, peripheral arterial disease, aortic plaque) & \\
$\mathrm{A}$ & Age 65-74 years & 1 \\
$\mathrm{Sc}$ & Sex category: female & 1 \\
\hline
\end{tabular}

on anticoagulant therapy required a transitory cessation during the two years of follow-up while, in the ROCKET-AF (rivaroxaban once daily oral, direct factor Xa inhibition compared with vitamin $\mathrm{K}$ antagonism for prevention of stroke and embolism in atrial fibrillation) study [42], 33\% of the patients experienced a temporary interruption of anticoagulant therapy. Forty percent of these interruptions were before surgical or invasive procedure.

In the perioperative context, the balance between thrombosis (in case of anticoagulation interruption) and bleeding (in case of anticoagulation continuation) should be assessed for each patient [43].

\subsection{The Thromboembolic Risk}

5.1.1. For the Arterial Side. In developed countries, atrial fibrillation (AF) affects about 1.5 to $2 \%$ of the population. This arrhythmia is associated with a 5-fold increased risk of stroke (AF is associated with 15-20\% of all strokes [44]), a 3-fold increased incidence in congestive heart failure, and a higher mortality [45]. Scores that assess thrombotic risk in the perioperative setting are not well established, whereas in certain chronic conditions risks like AF, stratification scores help in decision making when the risk of thrombosis and bleeding must be weighted $[46,47]$. The most widely used score is the $\mathrm{CHADS}_{2}$ score (congestive heart failure, hypertension, age > 75 years, diabetes, and prior stroke/transient ischemic attack). It is validated for predicting AF-related thromboembolic risk events and helps for the optimal selection of VKAs and
NOACs therapies $[46,47]$. Since 2010, the $\mathrm{CHA}_{2} \mathrm{DS}_{2}$-VASc score (including cardiovascular disease, atherosclerotic disease, and female sex as additional risk factors) (Table 4) improves the predictive value for thromboembolism. Only a small proportion of patients belong to the low risk and intermediate risk categories $[46,48]$. Patients with $\mathrm{CHA}_{2} \mathrm{DS}_{2}$ VASc score $\geq 2$ are considered at high risk of thrombosis [46].

The ARISTOTLE (apixaban for reduction in stroke and other thromboembolic events in atrial fibrillation) trial shows a superiority of apixaban over warfarin in terms of stroke or systemic embolism prevention [20,49] whatever the assessment of stroke risks by $\mathrm{CHADS}_{2}$ and $\mathrm{CHA}_{2} \mathrm{DS}_{2}$-VASc [50]. Actually, the assessment of periprocedural thrombotic risk is extrapolated from the risk outside the periprocedural period $[12]$.

5.1.2. For the Venous Side. Patients with venous thromboembolism are at high risks of recurrent thrombosis, thrombus propagation, and embolization until 3 months after diagnosis and initiation of anticoagulation therapy [51]. The risk of recurrence is conditioned by the underlying cause. It decreases if the etiology is provoked (e.g., trauma, fractures, and pregnancy), but if the underlying cause is idiopathic, the risk of recurrence is higher [52].

5.2. The Bleeding Risk. The bleeding risk is multifactorial and its assessment needs to consider patient-specific and procedure-specific variables [53]. 
TABLE 5: HAS-BLED score.

\begin{tabular}{lcc}
\hline HAS-Bled Score & Risk Factor & Points \\
\hline H & Hypertension (uncontrolled, systolic blood pressure $>160 \mathrm{mmHg})$ & 1 \\
$\mathrm{~A}$ & Abnormal renal function or liver function & 1 or 2(each 1) \\
S & Stroke & 1 \\
B & Bleeding history or predisposition to bleeding (e.g., bleeding diathesis, anemia) & 1 \\
L & Labile INR & 1 \\
E & Elderly (age $>65$ years) & 1 \\
D & Drug (antiplatelet, nonsteroïdal anti-inflammatory drugs) or alcohol abuse & 1 or 2(each 1) \\
\hline
\end{tabular}

\subsubsection{Patient-Specific Variables}

For the Arterial Side. HAS-BLED score is used to assess 1-year risk of major bleeding in patients with AF under VKAs [54] (Table 5). Other scores such as ATRIA [55] and HEMORR ${ }_{2}$ HAGES [56] scores are also used [57]. All these scores offer a modest predictive performance of the estimation of the bleeding risk in NOACs treated patients with AF. However, HAS-BLED and HEMORR ${ }_{2}$ HAGES scores are superior in terms of clinically relevant bleeding for patients on NOACs [58]. Nevertheless, a second analysis of the ARISTOTLE trial shows less bleeding under apixaban compared with warfarin, independently of the HAS-BLED score [50].

For the Venous Side. The RIETE score (Registro Informatizado de Enfermedad Tromboembólica) assesses the risk of fatal bleeding in VTE patients and seems better in predicting gastrointestinal than intracranial fatal bleeding [59].

5.2.2. Procedure-Specific Variables. There is little data available to identify the risk of blood loss related to the invasive procedure or surgery [60], except for cardiac surgery [61]. The estimation of bleeding risk for surgery/invasive procedure remains controversial for certain procedures and has low level of evidence [13]. Furthermore, there is a high intercenter variability in red cell blood loss for the main procedure, mainly reflecting differences in surgical techniques. Similarly, classifications into different surgery bleeding risks according to the severity of trauma and the risk of periprocedural bleeding [12,60,62-65] are not always easy to use in daily practice. Therefore, it is recommended to develop an institutional guideline and a hospital-wide policy concerning perioperative anticoagulation management in different procedures [63].

5.3. Interval between Last Dose and Invasive Procedure or Surgery. The interval between the last dose and the invasive procedure or surgery depends on the bleeding risk of the procedure and the drug half-life (Table 3 ).

5.3.1. The Invasive Procedure or Surgery. Some procedures defined as minimal procedures with little tissue trauma are at low risk for bleeding $[14,63,66]$ and can be achieved without interruption of NOACs (e.g., superficial skin and oral mucosal surgery, wound revisions, nonextraction dental treatment, or cataract surgery). Gastrointestinal endoscopic biopsy without cessation of $\mathrm{DE}$ seems to be safe according to current Japanese guidelines [67]. It is recommended to perform the procedure at the trough drug concentration (12 or 24 hours after the last intake) $[13,63,68]$.

5.3.2. Drug Metabolism and Elimination. The percentage of drug eliminated after 2, 3, 4, and 5 half-lives is $75 \%, 87.5 \%$, $93.8 \%$, and $96.9 \%$, respectively [69]. Dabigatran etexilate, rivaroxaban, and apixaban have different drug metabolic and elimination pathways (Table 3 ). Creatinine clearance $(\mathrm{CrCl})$ must be assessed by the Cockroft and Gault method. Estimation of renal function by Modification of Diet in Renal Disease Equation 4 (MDRD 4) leads to an overestimation of the renal function at lower levels. Thus, many elderly patients with AF would either become incorrectly eligible for NOACs or would receive a too high dose, which may explain the serious incidences of bleeding reported $[9,30]$.

Some specific populations have an increased half-life of NOACs' elimination and need therefore special attention. This concerns patients with renal or hepatic impairment, particularly the elderly with fluctuating renal function, diuretic use, hypovolemia, liver chronic infections, liver cirrhosis, alcohol abuse, obstructed bile flow, hepatorenal syndrome, and associated coagulopathy. Assessing both renal and liver function must be done preoperatively for every patient on NOACs. The three agents can be used in mild hepatic impairment (Child-Pugh A), while DE and apixaban are allowed in moderate hepatic impairment (Child-Pugh B), but not in severe hepatic impairment (Child-Pugh C) [70].

It is also important to check preoperatively any off-label use or misuse of these NOACs, including the concomitant medications (verapamil, dronedarone, ketoconazole, amiodarone, tacrolimus, etc.), older ages, and extreme body weights. All of these groups should probably require a longer interval of NOACs' arrest, and a measurement of the anticoagulant residual activity should be considered before an invasive procedure.

Several interval schemes based on expert's opinions are proposed taking into account NOACs' pharmacokinetics, patient, and/or type of invasive procedure or surgery (Table 6).

The "Groupe d'Intérêt en Hémostase Périopératoire" (GIHP) proposes a unique scheme: 1 day of interruption in case of low risk bleeding surgery or procedure and 5 for other procedures, whatever the molecule, renal function, and concomitant medications [13]. The duration of stopping is 
proposed empirically to ensure no residual anticoagulant effect in the absence of a validated antidote.

Except for minimal procedures which can be achieved without stopping NOACs, other experts or expert groups propose a window without any NOAC, according to the $\mathrm{CrCl}$ and/or the type of surgery. An interval of at least 48 hours (about 3 half-lives) should be maintained for a patient with a $\mathrm{CrCl}$ above $50 \mathrm{~mL} / \mathrm{min}$ to perform surgery or invasive procedure, whatever the molecule. The free interval is increased to at least 4 days for patients on $\mathrm{DE}$ with $\mathrm{CrCl}$ between 30 and $50 \mathrm{~mL} / \mathrm{min}$ or for patients on rivaroxaban/apixaban with a $\mathrm{CrCl}$ between 15 and $30 \mathrm{~mL} / \mathrm{min}$ (Table 6). Further large prospective studies are needed to confirm the safety of these perioperative procedures.

5.4. To Bridge or Not to Bridge during the Perioperative Interruption. For patients on VKA, the procedure is well established $[12,60]$. Guidelines recommend to bridge patients at high risk for thromboembolism (mechanical heart valve, AF, or VTE) with LMWH. For patients at low risk for thromboembolism, they suggest no bridging in case of stopping $[60,71]$. Patients classified as being at high risk have more than $10 \%$ annual risk for thromboembolism while this risk is reduced to less than $5 \%$ for those classified as being at low risk [60].

For VKAs, Siegal et al. [71] as well as Feng et al. [72] showed an increased risk of bleeding with similar thrombotic risk among patients who underwent periprocedural bridging therapy with heparin bridging. Recently, Omran et al. [73] have validated a HAS-BLED score $\geq 3$ as the most predictive variable for hemorrhage for patients who had heparin bridging during a perioperative interruption of VKAs before an elective invasive procedure.

Expert's opinions recommend no heparin bridging for NOACs [62, 63, 74], except the GIHP [13]. The last group proposes to stop NOACs 5 days before a surgery with medium or high risk of bleeding, to ensure a complete elimination of the drug in all patients. And if the patient is at high thromboembolic risk (e.g., AF with a history of stroke), they suggest bridging with LMWH or UFH.

Beyer-Westendorf et al. [14] had recently presented the first prospective data from a national registry that supported the concept of short-term interruption without heparin bridging.

They concluded that if a surgery or an invasive procedure requires a NOAC's arrest, most patients can safely interrupt NOACs for a short period without heparin bridging. In case of heparin bridging therapy, the rate of cardiovascular events is not reduced. There is a significantly higher rate of bleeding complications due to heparin bridging or major procedures. However, patients at cardiovascular risk undergoing major procedures may benefit from heparin bridging because their outcome in terms of cardiovascular risk is increased and because, in this particular setting, heparin bridging is not an independent factor for bleeding risk.

Those data do not support a systematic bridging therapy but highlight its probable benefit in patients at cardiovascular risk undergoing high risk surgery. Table 7 shows categories of procedures defined by the severity of tissue trauma and the risk for periprocedural bleeding [14].

During the ROCKET-AF trial, patients who required temporary interruption of anticoagulant therapy for surgery and invasive procedure were bridged only in $6 \%$ of the cases, predominantly by LMWH. The rate of major bleeding was similar in bridged and nonbridged patients. The incidence of bleeding (major and nonmajor clinically relevant bleeding according to International Society on Thrombosis and Hemostasis definitions [75]) was higher in case of bridging therapy, while stroke and systemic embolism were similar in both groups [42]. The study suffers several biases such as the use of bridging therapy in a nonrandomized way and the too low number of events.

Devices implants in most of Canadian centers are performed with NOAC interruption without LMWH bridging [76]. Again, this study demonstrates the necessity of an individual assessment of each patient, on a case-by-case basis [77].

Thus, there is no universal strategy for periprocedural management of NOACs, but a stepwise approach can be considered. Some prerequisites are essential to allow periprocedural decision (Table 8).

The decision about perioperative NOACs management should be written in the medical record.

\subsection{A Particular Case: Anesthesia Procedures}

5.5.1. Neuraxial Anesthesia. For patients without thrombotic risk (assessed by $\mathrm{CHA}_{2} \mathrm{D}_{2}$-VASc score), Benzon et al. [78] recommend 5 half-life intervals between NOAC's discontinuation and a neuraxial puncture (with or without epidural catheter placement). For patients with high risk of stroke or VTE, this interval can be shortened to 2 or 3 half-lives, or it can stay at 5 half-lives if LMWH bridging is associated. Llau and Ferrandis [79] provided recommendations based on NOAC's pharmacokinetics in the setting of thromboprophylaxis. For spinal anesthesia, if the puncture is atraumatic, the first dose of DE can be administrated 1-4 hours after the end of surgery and after 6-8 hours for rivaroxaban. If the puncture is traumatic or hemorrhagic, the first dose of DE or rivaroxaban is delayed by 24 hours. For epidural anesthesia, $\mathrm{DE}$ cannot be administrated if a permanent catheter is inserted. For rivaroxaban, the first dose after epidural anesthesia is administered 6-10 hours after the end of surgery. An interval of 18 hours is recommended before the removal of the epidural catheter (22-26 hours for elderly patients) and at least 4 hours after removal. The European Society of Anaesthesiology (ESA) [80] recommends extreme caution when using neuraxial blockade in the presence of rivaroxaban/ apixaban. For dabigatran, the manufacturer advises against its use in the presence of neuraxial blockade. Because of a potential risk of retroperitoneal hematoma in lumbar plexus and paravertebral blocks, ESA recommends the same guidelines for these two peripheral nerve blocks as for neuraxial blockades $[78,80]$. 


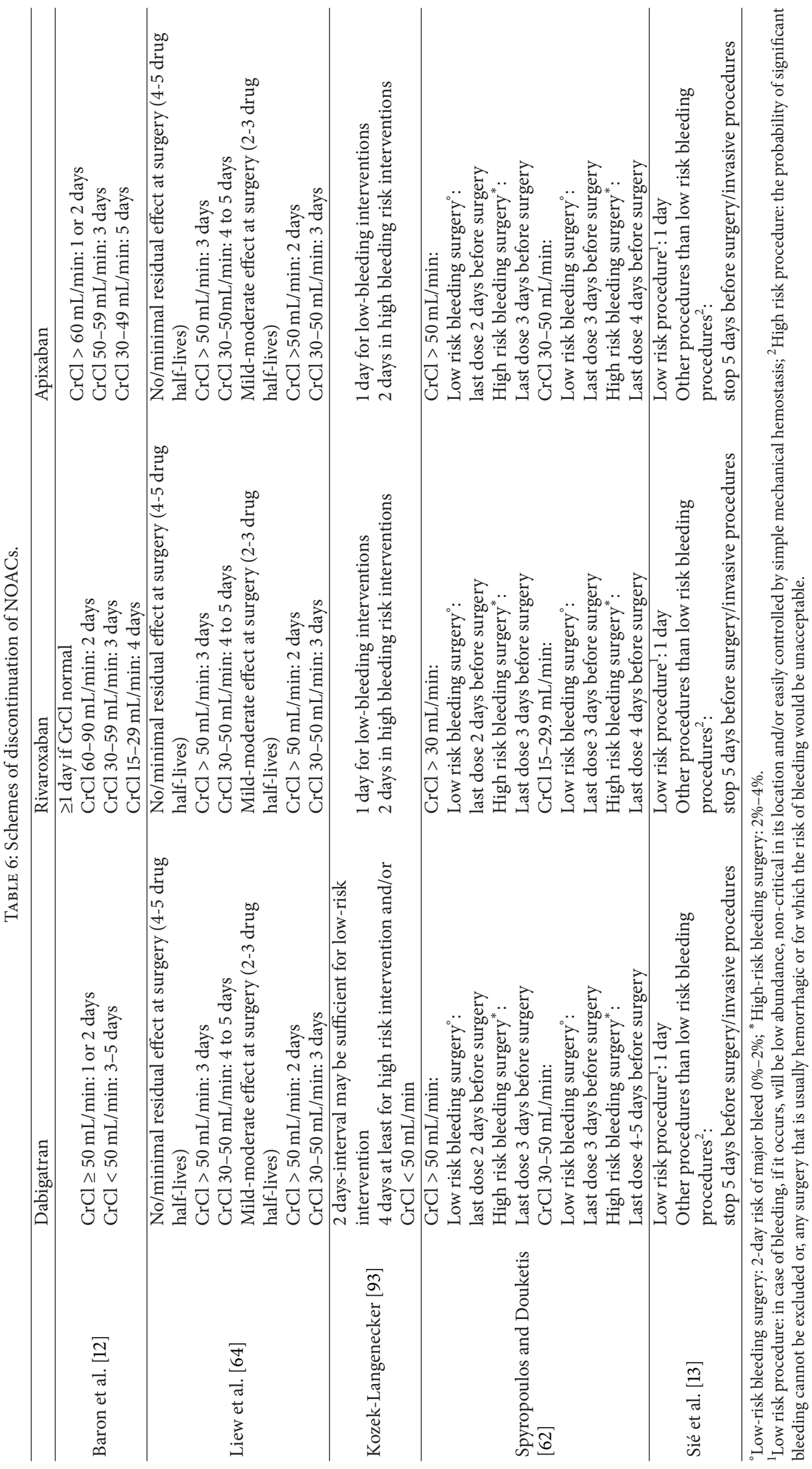


TABLE 7: Categories of procedures according to the severity of tissue trauma and the risk for peri-procedural bleeding.

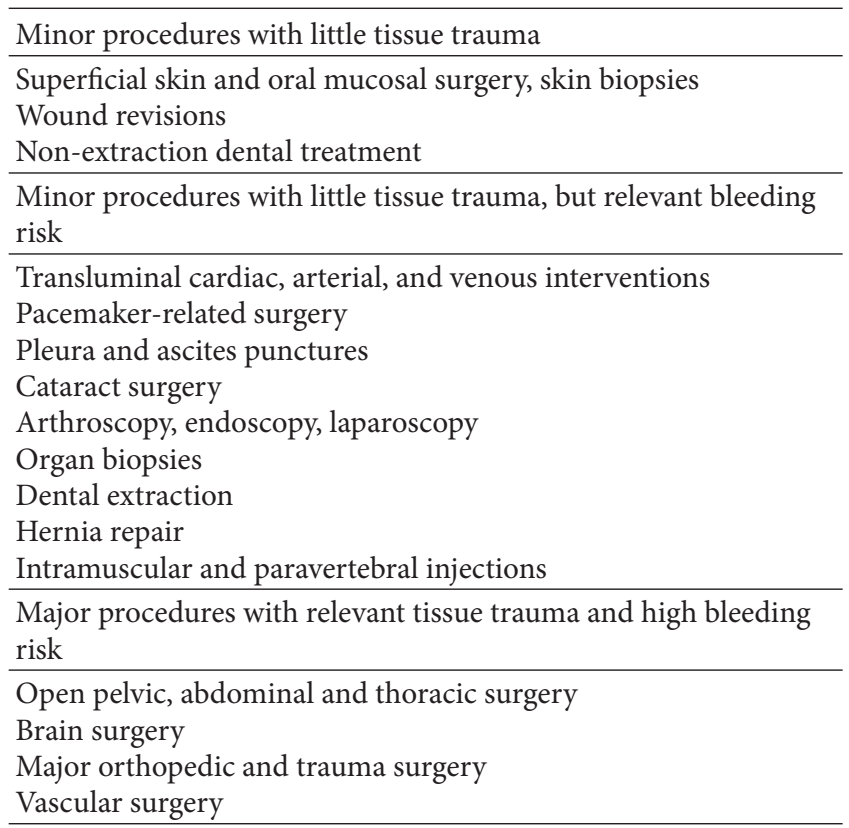

5.5.2. Other Peripheral Nerve Blocks. ESA does not routinely apply the same guidelines as for neuraxial blockades [81], but the American Society of Regional Anesthesia (ASRA) does [78].

5.6. A Particular Case: Atrial Fibrillation Ablation. Uninterrupted warfarin therapy with therapeutic anticoagulation has been shown to be associated with lower risk of periprocedural thromboembolic events after AF ablation and is increasingly being accepted as the preferred anticoagulation strategy [82]. However, increasingly more patients are being treated with NOACs, thereby complicating the periprocedural anticoagulation management.

For dabigatran, there is no consensus regarding the management of patients taking dabigatran who are referred for AF ablation. The results depend on the period of dabigatran interruption. Nearly uninterrupted anticoagulation (holding the morning dose), which theoretically has a better protection from periprocedural thromboembolism, was associated with both increased bleeding and thromboembolic events, especially in the nonparoxysmal AF [83]. Other observational studies with a more interrupted approach showed equivalent bleeding and embolic events compared to therapeutic warfarin [84-87].

For rivaroxaban, uninterrupted rivaroxaban appears to be a feasible and safe alternative to uninterrupted warfarin therapy in patients undergoing AF ablation. Future larger and randomized trials are needed to confirm those preliminary data [83].

\section{Management in an Emergency Situation}

In case of a surgery or invasive procedure, the degree of emergency should be assessed in order to decrease the bleeding
TABLE 8: Essential prerequisites allowing perioperative decisions.

\begin{tabular}{ll}
\hline \multirow{3}{*}{ Molecule } & Type \\
& $\begin{array}{l}\text { Dose } \\
\text { Indication }\end{array}$ \\
\hline \multirow{3}{*}{ Patient } & Thromboembolic risk_bleeding risk \\
& $\begin{array}{l}\text { Renal function (CrCl-Cockroft and Gault formula) } \\
\text { Hepatic function } \\
\text { Concomitant drugs }\end{array}$ \\
& Approved NOAC's indication \\
\hline \multirow{2}{*}{ Procedure } & $\begin{array}{l}\text { Type and technique } \\
\text { Bleeding risk } \\
\text { Date of its achievement (Day 0) }\end{array}$ \\
\hline \multirow{2}{*}{ Anesthesia } & $\begin{array}{l}\text { General and/or regional (neuroaxial or peripheral } \\
\text { nerve blocks) }\end{array}$ \\
\hline
\end{tabular}

risk: NOACs must be discontinued, timing of the last dose intake should be known, and if possible, invasive procedure should be delayed until the NOACs reach trough concentration. Waiting and postponing semiurgent procedures may be a reasonable strategy to prevent bleeding. In case of bleeding emergencies under NOACs, several difficulties are encountered: there is currently no antidote and no rapid quantitative measurement of the anticoagulant effect (see laboratory testing for NOACs in a perioperative setting), strategies to reverse the anticoagulant effect are poor, and, depending on the residual concentration of NOACs, administration of factors is rendered ineffective $[15,63]$.

It is very important to establish a hospital-wide policy for bleeding management in patients taking NOACs, based on the available blood products and laboratory assays in each institution. The procedure must be easily accessible (e.g., intranet site, personal digital assistant (PDA)). Some workgroups propose algorithms based on NOAC's plasma concentration, but their quantitative measurements are not currently routinely performed [88].

In case of bleeding that does not respond to supportive measures (surgical hemostasis, embolization, fluid replacement, etc.) in patients taking $\mathrm{DE}$, ensure adequate diuresis and suggest hemodialysis. Dabigatran is $35 \%$ bound to plasma proteins, theoretically allowing its elimination by hemodialysis, but clinical experience is limited [89-91]. However, hemodialysis might be more effective than unspecific reversal treatment with factor concentrates. A single-center study including patients with end-stage renal disease measured DE elimination with hemodialysis. Four hours of hemodialysis with $200 \mathrm{~mL} / \mathrm{min}$ and $400 \mathrm{~mL} / \mathrm{min}$ targeted blood flow removed $48.8 \%$ and $59.3 \%$ of total dabigatran from the central compartment, respectively. There was a linear relation between anticoagulant activity of dabigatran and its plasma levels. Minor redistribution of dabigatran $(<16 \%)$ after the end of the hemodialysis session occurred. These results support hemodialysis as a suitable approach to eliminate dabigatran in emergency situations [92]. An extracorporeal renal replacement therapy filter can also be easily added during emergent cardiac surgery [93]. However, a 
TABle 9: Coagulation factor and pro-hemostatic agents.

\begin{tabular}{ll}
\hline $\begin{array}{l}\text { Concentrate of factors (II, (VII), IX et X): prothrombin complex } \\
\text { concentrate, PCC, PPSB (Cofact, Confidex, Octaplex, Beriplex) }\end{array}$ & 25 U/kg, once or two times* \\
\hline $\begin{array}{l}\text { Concentrate of activated factors: idem PCC + VIIa, FEIBA, } \\
\text { (FEIBA) }\end{array}$ & $50 \mathrm{IE} / \mathrm{kg}$, max 200 IE/kg/day \\
\hline Factor VIIa: (Novoseven) & Needs further evaluation: $90 \mu \mathrm{g} / \mathrm{kg}$ \\
\hline $\begin{array}{l}\text { Antifibrinolytics (Tranexamic acid (Exacyl), Aminocaproïc acid), } \\
\text { Desmopressin (Minirin) }\end{array}$ & No clinical data in this context \\
\hline \begin{tabular}{l} 
Fresh Frozen Plasma (FFP) \\
\hline Protamin, vitamin K
\end{tabular} & $\begin{array}{l}\text { Not useful to reverse anticoagulation, expand plasma volume in } \\
\text { case of massive transfusion }\end{array}$ \\
\hline $\begin{array}{l}{ }^{*} \text { PCC or aPCC utilization is based of few experimental data, can be considered if immediate hemostatic support is essential in case of life-threating bleeding } \\
\text { (need for } \geq 4 \text { red cells transfusions and exogenous cathecolamins for hemodynamic stabilization). }\end{array}$
\end{tabular}

special care to bleeding at the punctures sites is necessary and therefore ultrasound guided techniques are very useful. Hemoperfusion over a charcoal filter is under evaluation [89]. Oral activated charcoal may be effective only in case of a recent ingestion within 2 hours [89].

An analysis of major bleeding patients in the RE-LY study concludes that the overall resources required to manage bleeding were not greater than those after warfarin-related bleeding. For patients treated with DE, red cells transfusions were higher, plasma transfusions were lower, the stay in intensive care unit was shorter, and there was a lower trend in mortality compared with patients treated with warfarin. Based on these results, they concluded on a safety profile of DE [94].

There is currently no specific hemostatic agent for the reversal of NOACs in case of bleeding or in emergency situations but different antidotes are under development. Andexanet alfa (PRT064445) is a truncated form of enzymatically inactive FXa: it reverses dose-dependently the inhibitory activity and corrects ex vivo clotting times [95]. For dabigatran, a humanized selective and specific monoclonal antibody fragment (idarucizumab) is under development [96]. Aripazine (PER977), another small synthetic molecule, reverses anticoagulant activity of all clinically used NOACs in rat bleeding models [97].

Hemostatic agents used for life-threatening bleeding are shown in Table 9.

\section{Laboratory Testing for NOACs in a Perioperative Setting}

NOACs do not require routine coagulation monitoring. This point is considered as an advantage for the physicians and an improvement of quality of life for their patients. However, point measurement of NOACs may be required in several clinical situations including the perioperative setting $[8,10$, 11, 78, 98, 99].

For VKAs, it is well established that, at time of surgery (INR on the day before surgery), an elevated INR (i.e., $\geq 2$ ) will increase the risk of bleeding and a near normal or normal INR (i.e., $\leq 1.5$ ) will not [60]. But, for NOACs, the residual drug level that can be considered as safe is not known, except for dabigatran. The residual dabigatran concentration that is recommended before special intervention (such as surgery) is provided in the Committee for Medicinal Products for Human Use (CHMP) assessment report from the European Medicine Agency that states "(...) dabigatran concentration under $48 \mathrm{ng} / \mathrm{mL}$ is equivalent to at least 75\% of dabigatran's elimination and should be recommended" [100]. A French group of experts called GIHP proposed the threshold of $30 \mathrm{ng} / \mathrm{mL}$ (for dabigatran and rivaroxaban) [88].

Details of these recommendations are presented in Table 10 [88].

\subsection{Which Laboratory Tests Should We Use in the Perioperative} Setting and How to Interpret Them? Activated partial thromboplastin time (aPTT) and prothrombin time (PT) are global assays not reflecting plasma NOACs concentrations. They are not suitable for precise quantification of the anticoagulant effect. Thrombin time (TT) was demonstrated to be too sensitive towards dabigatran $[89,101]$. However, this may guide the clinician in the perioperative setting since a normal TT indicates no clinically relevant anticoagulant effect of dabigatran. The strong sensitivity of TT towards dabigatran leads to the development of a calibrated diluted thrombin time (dTT) with dabigatran standards to calculate the dabigatran plasma concentration. Several studies showed that the dTT or the ecarin chromogenic assay (ECA) highly correlates with dabigatran plasma concentrations measured by LCMS/MS in patient's plasma [102-104]. However, one limitation of dTT is that, in case of switching therapy (i.e., from heparins/heparinoids to dabigatran etexilate or from hirudin and derivatives to dabigatran etexilate), they will be slightly influenced by the presence of such inhibitors in the plasma. This implies the necessity of an accurate anamnesis of the drugs taken by the patient to avoid overestimation of drug concentrations in plasma. In addition, for the accurate determination of dabigatran plasma concentrations below $50 \mathrm{ng} / \mathrm{mL}$, the more sensitive liquid chromatography-mass spectrometry/mass spectrometry (LC-MS/MS) method is still required $[102,104]$.

For rivaroxaban, chromogenic anti-Xa assay has been proven to accurately estimate the plasma rivaroxaban concentrations $>30 \mathrm{ng} / \mathrm{mL}$ [105]. Due to their good sensitivity 
TABle 10: Perioperative management of NOACs (dabigatran and rivaroxaban)_Proposal for recommendations from the GIHP ("Groupe d'Intérêt en Hémostase Périopératoire").

\begin{tabular}{ll}
\hline Measured concentration & Recommendations \\
\hline$<30 \mathrm{ng} / \mathrm{mL}$ & Operate \\
\hline $30-200 \mathrm{ng} / \mathrm{mL}$ & $\begin{array}{l}\text { Wait up to } 12 \mathrm{~h} \text { and obtain new dosage or (if time is not compatible with emergency) } \\
\text { Operate, if abnormal bleeding: antagonise the anticoagulant effect }\end{array}$ \\
\hline \multirow{2}{*}{$200-400 \mathrm{ng} / \mathrm{mL}$} & $\begin{array}{l}\text { Wait up to } 12 \mathrm{~h} \text { and obtain new dosage or (if time is not compatible with emergency) } \\
\text { Maximise delay surgery } \\
\text { Discuss hemodialysis, especially if } \mathrm{CrCl}<50 \mathrm{~mL} / \mathrm{min} \text { (with dabigatran only) } \\
\text { Operate, if abnormal bleeding: antagonise }\end{array}$ \\
\hline $400 \mathrm{ng} / \mathrm{mL}$ & $\begin{array}{l}\text { Overdose-Major haemorrhagic risk } \\
\text { Discuss haemodialysis before surgery (with dabigatran only) }\end{array}$ \\
\hline
\end{tabular}

TABLE 11: Influence of dabigatran, rivaroxaban and apixaban on coagulation tests used in the perioperative setting.

\begin{tabular}{|c|c|c|c|}
\hline & Dabigatran & Rivaroxaban & Apixaban \\
\hline Prothrombin Time (PT) & $\begin{array}{l}\text { Time prolonged }+ \text { (relative to } \\
\text { reagent sensitivity) }\end{array}$ & $\begin{array}{l}\text { Time prolonged }+ \text { to }+++ \\
\text { (relative to reagent sensitivity) }\end{array}$ & $\begin{array}{l}\text { Time non-prolonged or } \\
\text { prolonged + (relative to reagent } \\
\text { sensitivity) }\end{array}$ \\
\hline $\begin{array}{l}\text { Activated Partial } \\
\text { Thromboplastin Time (aPTT) }\end{array}$ & $\begin{array}{l}\text { Time prolonged }+ \text { to }+++ \\
\text { (relative to reagent sensitivity) }\end{array}$ & $\begin{array}{l}\text { Time prolonged }+ \text { (relative to } \\
\text { reagent sensitivity) }\end{array}$ & $\begin{array}{l}\text { Time prolonged + (relative to } \\
\text { reagent sensitivity) }\end{array}$ \\
\hline $\begin{array}{l}\text { PT-based coagulation factors } \\
\text { measurement } \\
(\text { II, VII, IX, X) }\end{array}$ & $\begin{array}{l}\text { Slightly decreased (depending on } \\
\text { the reagent) }\end{array}$ & $\begin{array}{l}\text { Slightly decreased (depending on } \\
\text { the reagent) }\end{array}$ & $\begin{array}{l}\text { Slightly decreased (depending on } \\
\text { the reagent) }\end{array}$ \\
\hline $\begin{array}{l}\text { APTT-based coagulation } \\
\text { factors measurement } \\
\text { (VIII, IX, XI) }\end{array}$ & $\begin{array}{l}\text { Slightly decreased (depending on } \\
\text { the reagent) }\end{array}$ & $\begin{array}{l}\text { Slightly decreased (depending on } \\
\text { the reagent) }\end{array}$ & $\begin{array}{l}\text { Slightly decreased (depending on } \\
\text { the reagent) }\end{array}$ \\
\hline Fibrinogen & $\begin{array}{l}\text { No influence or slightly decrease } \\
\text { (depending on the reagent) }\end{array}$ & No influence & No influence \\
\hline Thrombin Time & Time prolonged +++++ & No influence & No influence \\
\hline $\begin{array}{l}\text { Anti-Xa based antithrombin } \\
\text { measurement }\end{array}$ & No influence & Increased: $10 \%$ per $100 \mathrm{ng} / \mathrm{mL}$ & Increased: $10 \%$ per $100 \mathrm{ng} / \mathrm{mL}$ \\
\hline $\begin{array}{l}\text { Anti-IIa based antithrombin } \\
\text { measurement }\end{array}$ & Increased: $5-10 \%$ per $100 \mathrm{ng} / \mathrm{mL}$ & No influence & No influence \\
\hline
\end{tabular}

towards the inhibition of FXa by apixaban, chromogenic anti-Xa assays calibrated with specific apixaban calibrators should be performed to estimate plasma drug concentration [106-108]. However, taking into account the lower sensitivity of chromogenic assays compared to LC-MS/MS and the variability of coagulation analysers that may further increase the imprecision at the lowest concentrations, detection and quantitation of lower levels ( $<30 \mathrm{ng} / \mathrm{mL}$ for rivaroxaban and $<15 \mathrm{ng} / \mathrm{mL}$ for apixaban) still require LC-MS/MS analyses $[108,109]$.

Even if these specific coagulation tests to assess NOACs are promising, they suffer from difficulties to be implemented easily in the clinical setting. Moreover, assessment of lower levels of NOACs encountered in the perioperative setting is challenging due to the limit of quantitation of these tests but improvements in the low range are under development by several companies.

In addition, to correctly interpret the results of laboratory assay, some information needs to be collected: drug, indication, and the timing of the last dose administration (due to the short half-life of NOACs) [110]. The interpretation of the results requires education of the front staff in many specialties [98]. Finally, it has been clearly shown that NOACs influence the results of different coagulation assays used in the perioperative setting leading to misinterpretations [41] (Table 11).

7.2. A Particular Case: Atrial Fibrillation Ablation. The ideal management of oral anticoagulation during catheter ablation for AF 112-114 is still controversial with a wide range of procedures available. During AF ablation, it is now recommended to achieve and maintain an ACT of 300 to 400 seconds in order to reduce the risk of systemic thromboembolism [111]. However, the ACT is affected by a lot of preanalytical [112] and analytical variables $[113,114]$. Finally, target ACT should be redetermined for the periprocedural use of NOACs for AF ablation [111-117].

\section{Resumption of the NOACs after Invasive Procedure or Surgery}

Once again, in the postoperative period, the bleeding risk must be weighted with the thromboembolic risk; however the 
risk for major bleeding exceeds the risk for thromboembolic complications after surgery [118]. Regarding the thromboembolic risk, Kaatz et al. [119] concluded that patients with chronic AF had twice as much risks of postoperative stroke, especially in neurosurgery and vascular surgery. The bleeding risk in the postoperative period is mainly due to patient's characteristics (bridging therapy, mitral mechanic heart valve, active cancer, prior bleeding history, and reinitiation of heparin therapy within 24 hours after surgery), even if a premature heparin resumption is an avoidable risk factor [120]. But first of all surgical bleeding risk must be under control [121]. For NOACs, given the fact that full anticoagulation occurs between 2 and 4 hours (Table 3 ) and that no antidote is available, resumption of DE, rivaroxaban, and apixaban should be performed at least 48 hours after the high risk procedures [12]. This delay can expose patients at risk for thromboembolism. Twenty-four hours are recommended before resuming oral anticoagulation after a procedure at low risk of bleeding $[60,62]$. Other schemes exist in order to minimize bleeding risks: consider a stepwise resumption of NOACs $[16,77]$ or administer prophylactic doses of LMWH early after the surgery, and restart full doses of NOACs only after 3 or 4 days [122]. Heparin bridging can be useful if the patient cannot tolerate oral medication (e.g., in ileus or postoperative nausea and vomiting) [66]. In the postoperative setting, it is essential to reassess patient's renal function, especially for elderly who are subject to dehydration and for patients taking DE. For LMWH, doses must be adapted in case of extreme body weight (body mass index above $30 \mathrm{~kg} / \mathrm{m}^{2}$ ) and poor renal function. If $\mathrm{CrCl}$ is less than $30 \mathrm{~mL} / \mathrm{min}$, the use of unfractionated heparin is more indicated $[12,123]$.

\section{Conclusions}

In the field of oral anticoagulation, clinicians will be more frequently confronted about their management of NOACs in the pre- and postoperative setting. Prerequisites are essential for NOAC's pharmacokinetics, indications, drug interactions, and alterations of standard laboratory assays. Actual data are based mainly on expert's opinions, except one national registry study. In some situation, interruption periods of NOACs are necessary and should be based on their respective half-life, on the bleeding risk of procedures, and on the thromboembolic risk of patients. Some scores such as $\mathrm{CHA}_{2} \mathrm{DS}_{2}$-VASc and HAS-BLED should help clinicians in their decisions. Given their shorter half-life, no heparin bridging during the interruption interval seems necessary, except for patients at high cardiovascular risk undergoing major surgery.

Further clinical trials over perioperative management of patients under NOACs are still required. Emergency surgeries, invasive procedures, or bleeding patients remain a real challenge given the absence of antidote. Possibilities of reversal are poor and based on few experimental data and case reports. Furthermore, rapid quantitative measurements of the anticoagulant effect are not available in most institutions. Awaiting future clinical trial data, it seems to be important to establish a hospital-wide policy for bleeding management in patients taking NOACs, in accordance to the available blood products and laboratory assays of each institution.

\section{Conflict of Interests}

The authors have no conflict of interests to disclose.

\section{Authors' Contribution}

Anne-Sophie Dincq and Sarah Lessire contributed equally to this work.

\section{References}

[1] S. Husted, R. de Caterina, F. Andreotti et al., "Non-vitamin K antagonist oral anticoagulants (NOACs): no longer new or novel," Thrombosis and Haemostasis, vol. 111, no. 5, pp. 781-782, 2014.

[2] European Medicine Agency, Xarelto: Summary of Product Characteristics, 2013, http://www.ema.europa.eu/docs/en_GB/ document_library/EPAR_-_Product_Information/human/000944/ WC500057108.pdf.

[3] European Medicine Agency, "Pradaxa: Summary of Product Characteristics," 2013, http://www.ema.europa.eu/docs/en_GB/ document_library/EPAR_-_Product_Information/human/000829/ WC500041059.pdf.

[4] European Medicine Agency, Eliquis: Summary of Product Characteristics, 2014, http://www.ema.europa.eu/docs/en_GB/ document_library/EPAR_-_Product_Information/human/002148/ WC500107728.pdf.

[5] Food and Drug Administration, "Pradaxa: Full Prescribing Information,” 2013, http://www.accessdata.fda.gov/drugsatfda_ docs/label/2013/022512s017lbl.pdf.

[6] Food and Drug Administration, Xarelto: Full Prescribing Information, 2014, http://www.accessdata.fda.gov/drugsatfda_ docs/label/2013/022406s004lbl.pdf.

[7] Food and Drug Administration-Eliquis: Full Prescribing Information, 2014, http://www.accessdata.fda.gov/drugsatfda docs/label/2013/022512s017lbl.pdf.

[8] J. H. Levy, D. Faraoni, J. L. Spring, J. D. Douketis, and C. M. Samama, "Managing new oral anticoagulants in the perioperative and intensive care unit setting," Anesthesiology, vol. 118, no. 6, pp. 1466-1474, 2013.

[9] A. Helldén, I. Odar-Cederlöf, G. Nilsson et al., "Renal function estimations and dose recommendations for dabigatran, gabapentin and valaciclovir: a data simulation study focused on the elderly," BMJ Open, vol. 3, no. 4, Article ID e002686, 2013.

[10] M. M. Samama, J. Amiral, C. Guinet, L. L. Flem, and J. Seghatchian, "Monitoring plasma levels of factor Xa inhibitors: how, why and when?" Expert Review of Hematology, vol. 6, no. 2, pp. 155-164, 2013.

[11] H. Ten Cate, "Monitoring new oral anticoagulants, managing thrombosis, or both?" Thrombosis and Haemostasis, vol. 107, no. 5, pp. 803-805, 2012.

[12] T. H. Baron, P. S. Kamath, and R. D. McBane, "Management of antithrombotic therapy in patients undergoing invasive procedures," The New England Journal of Medicine, vol. 368, no. 22, pp. 2113-2124, 2013. 
[13] P. Sié, C. M. Samama, A. Godier et al., "Surgery and invasive procedures in patients on long-term treatment with direct oral anticoagulants: thrombin or factor-Xa inhibitors. Recommendations of the Working Group on perioperative haemostasis and the French Study Group on thrombosis and haemostasis," Archives of Cardiovascular Diseases, vol. 104, no. 12, pp. 669-676, 2011.

[14] J. Beyer-Westendorf, V. Gelbricht, K. Forster et al., "Peri-interventional management of novel oral anticoagulants in daily care: results from the prospective Dresden NOAC registry," European Heart Journal, 2014.

[15] D. M. Siegal and M. A. Crowther, "Acute management of bleeding in patients on novel oral anticoagulants," European Heart Journal, vol. 34, no. 7, pp. 489-500, 2013.

[16] S. Schulman and M. A. Crowther, "How I treat with anticoagulants in 2012: new and old anticoagulants, and when and how to switch," Blood, vol. 119, no. 13, pp. 3016-3023, 2012.

[17] J. L. Mega, E. Braunwald, S. D. Wiviott et al., "Rivaroxaban in patients with a recent acute coronary syndrome," The New England Journal of Medicine, vol. 366, no. 1, pp. 9-19, 2012.

[18] R. Bauersachs, S. D. Berkowitz, B. Brenner et al., "Oral rivaroxaban for symptomatic venous thromboembolism," New England Journal of Medicine, vol. 363, pp. 2499-2510, 2010.

[19] S. Schulman, A. K. Kakkar, S. Z. Goldhaber et al., "Treatment of acute venous thromboembolism with dabigatran or warfarin and pooled analysis," Circulation, vol. 129, no. 7, pp. 764-772, 2014.

[20] C. B. Granger, J. H. Alexander, J. J. McMurray et al., "Apixaban versus warfarin in patients with atrial fibrillation," The New England Journal of Medicine, vol. 365, pp. 981-992, 2011.

[21] M. R. Patel, K. W. Mahaffey, J. Garg et al., "Rivaroxaban versus warfarin in nonvalvular atrial fibrillation," The New England Journal of Medicine, vol. 365, no. 10, pp. 883-891, 2011.

[22] S. J. Connolly, M. D. Ezekowitz, S. Yusuf et al., "Dabigatran versus warfarin in patients with atrial fibrillation," The New England Journal of Medicine, vol. 361, no. 27, pp. 1139-1151, 2009.

[23] M. R. Lassen, A. Gallus, G. E. Raskob, G. Pineo, D. Chen, and L. M. Ramirez, "Apixaban versus enoxaparin for thromboprophylaxis after hip replacement," The New England Journal of Medicine, vol. 363, no. 26, pp. 2487-2498, 2010.

[24] M. R. Lassen, G. E. Raskob, A. Gallus, G. Pineo, D. Chen, and P. Hornick, "Apixaban versus enoxaparin for thromboprophylaxis after knee replacement (ADVANCE-2): a randomised doubleblind trial," The Lancet, vol. 375, no. 9717, pp. 807-815, 2010.

[25] B. I. Eriksson, O. E. Dahl, N. Rosencher et al., "Oral dabigatran etexilate vs. subcutaneous enoxaparin for the prevention of venous thromboembolism after total knee replacement: the RE-MODEL randomized trial," Journal of Thrombosis and Haemostasis, vol. 5, no. 11, pp. 2178-2185, 2007.

[26] B. I. Eriksson, O. E. Dahl, M. H. Huo et al., "Oral dabigatran versus enoxaparin for thromboprophylaxis after primary total hip arthroplasty (RE-NOVATE II): a randomised, double-blind, non-inferiority trial," Thrombosis and Haemostasis, vol. 105, no. 4, pp. 721-729, 2011.

[27] B. I. Eriksson, A. K. Kakkar, A. G. Turpie et al., "Oral rivaroxaban for the prevention of symptomatic venous thromboembolism after elective hip and knee replacement," The Journal of Bone and Joint Surgery, vol. 91, pp. 636-644, 2009.

[28] B. I. Eriksson, D. J. Quinlan, and J. I. Weitz, "Comparative pharmacodynamics and pharmacokinetics of oral direct thrombin and factor Xa inhibitors in development," Clinical Pharmacokinetics, vol. 48, no. 1, pp. 1-22, 2009.
[29] J. Stangier and A. Clemens, "Pharmacology, pharmacokinetics, and pharmacodynamics of dabigatran etexilate, an oral direct thrombin inhibitor," Clinical and Applied Thrombosis/ Hemostasis, vol. 15, supplement 1, pp. 9S-16S, 2009.

[30] P. K. Maccallum, R. Mathur, S. A. Hull et al., "Patient safety and estimation of renal function in patients prescribed new oral anticoagulants for stroke prevention in atrial fibrillation: a cross-sectional study," BMJ Open, vol. 3, Article ID e003343, 2013.

[31] D. W. Cockcroft and M. H. Gault, "Prediction of creatinine clearance from serum creatinine," Nephron, vol. 16, no. 1, pp. 3141, 1976.

[32] R. Ferrandis, J. Castillo, J. de Andrés et al., "The perioperative management of new direct oral anticoagulants: a question without answers," Thrombosis and Haemostasis, vol. 110, no. 3, pp. 515-522, 2013.

[33] J. H. Levy, N. S. Key, and M. S. Azran, "Novel oral anticoagulants : implications in the perioperative setting," Anesthesiology, vol. 113, no. 3, pp. 726-745, 2010.

[34] J. Stangier, K. Rathgen, H. Stähle, D. Gansser, and W. Roth, "The pharmacokinetics, pharmacodynamics and tolerability of dabigatran etexilate, a new oral direct thrombin inhibitor, in healthy male subjects," British Journal of Clinical Pharmacology, vol. 64, no. 3, pp. 292-303, 2007.

[35] W. Mueck, J. Stampfuss, D. Kubitza, and M. Becka, "Clinical pharmacokinetic and pharmacodynamic profile of rivaroxaban," Clinical Pharmacokinetics, vol. 53, no. 1, pp. 1-16, 2014.

[36] J. D. Douketis, "Pharmacologic properties of the new oral anticoagulants: a clinician-oriented review with a focus on perioperative management," Current Pharmaceutical Design, vol. 16, no. 31, pp. 3436-3441, 2010.

[37] N. Raghavan, C. E. Frost, Z. Yu et al., "Apixaban metabolism and pharmacokinetics after oral administration to humans," Drug Metabolism and Disposition, vol. 37, no. 1, pp. 74-81, 2009.

[38] J. Stangier and A. Clemens, "Pharmacology, pharmacokinetics, and pharmacodynamics of dabigatran etexilate, an oral direct thrombin inhibitor," Clinical and Applied Thrombosis/Hemostasis, vol. 15, supplement 1, pp. 9S-16S, 2009.

[39] S. Lessire, A.-S. Dincq, J. Douxfils et al., "Preventive strategies against bleeding due to nonvitamin $\mathrm{K}$ antagonist oral anticoagulants," BioMed Research International, vol. 2014, Article ID 616405, 14 pages, 2014.

[40] V. Pengo, L. Crippa, A. Falanga et al., "Questions and answers on the use of dabigatran and perpectives on the use of other new oral anticoagulants in patients with atrial fibrillation; a consensus document of the Italian federation of thrombosis centers (FCSA)," Thrombosis and Haemostasis, vol. 106, no. 5, pp. 868876, 2011.

[41] J. S. Healey, J. Eikelboom, J. Douketis et al., "Periprocedural bleeding and thromboembolic events with dabigatran compared with warfarin: results from the randomized evaluation of long-term anticoagulation therapy (RE-LY) randomized trial," Circulation, vol. 126, no. 3, pp. 343-348, 2012.

[42] M. W. Sherwood, J. D. Douketis, M. R. Patel et al., "Outcomes of temporary interruption of rivaroxaban compared with warfarin in patients with nonvalvular atrial fibrillation: results from the rivaroxaban once daily, oral, direct factor Xa inhibition compared with vitamin $\mathrm{K}$ antagonism for prevention of stroke and embolism trial in atrial fibrillation (ROCKET AF)," Circulation, vol. 129, pp. 1850-1859, 2014.

[43] A. C. Spyropoulos, R. M. Bauersachs, H. Omran, and M. Cohen, "Periprocedural bridging therapy in patients receiving chronic 
oral anticoagulation therapy," Current Medical Research and Opinion, vol. 22, no. 6, pp. 1109-1122, 2006.

[44] P. A. Wolf, R. D. Abbott, and W. B. Kannel, "Atrial fibrillation as an independent risk factor for stroke: the Framingham study," Stroke, vol. 22, no. 8, pp. 983-988, 1991.

[45] A. J. Camm, G. Y. Lip, R. de Caterina et al., "2012 focused update of the ESC guidelines for the management of atrial fibrillation: an update of the 2010 ESC guidelines for the management of atrial fibrillation-developed with the special contribution of the European Heart Rhythm Association," Europace, vol. 14, no. 10, pp. 1385-1413, 2012.

[46] G. Y. H. Lip, R. Nieuwlaat, R. Pisters, D. A. Lane, and H. J. G. M. Crijns, "Refining clinical risk stratification for predicting stroke and thromboembolism in atrial fibrillation using a novel risk factor-based approach: the Euro Heart Survey on atrial fibrillation," Chest, vol. 137, no. 2, pp. 263-272, 2010.

[47] G. Y. H. Lip, F. Andreotti, L. Fauchier et al., "Bleeding risk assessment and management in atrial fibrillation patients: executive summary of a position document from the european heart rhythm association [EHRA], endorsed by the european society of cardiology [ESC] working group on thrombosis," Thrombosis and Haemostasis, vol. 106, no. 6, pp. 997-1011, 2011.

[48] I. G. E. Zarraga and J. Kron, "Oral anticoagulation in elderly adults with atrial fibrillation: integrating new options with old concepts," Journal of the American Geriatrics Society, vol. 61, no. 1, pp. 143-150, 2013.

[49] R. D. Lopes, J. H. Alexander, S. M. Al-Khatib et al., "Apixaban for reduction in stroke and other ThromboemboLic events in atrial fibrillation (ARISTOTLE) trial: design and rationale," The American Heart Journal, vol. 159, no. 3, pp. 331-339, 2010.

[50] R. D. Lopes, S. M. Al-Khatib, L. Wallentin et al., "Efficacy and safety of apixaban compared with warfarin according to patient risk of stroke and of bleeding in atrial fibrillation: a secondary analysis of a randomised controlled trial," The Lancet, vol. 380, no. 9855, pp. 1749-1758, 2012.

[51] C. Kearon, E. A. Akl, A. J. Comerota et al., "Antithrombotic therapy for VTE disease: antithrombotic therapy and prevention of thrombosis, 9th ed: American College of Chest Physicians evidence-based clinical practice guidelines," Chest, vol. 141, no. 2, pp. e419S-e494S, 2012.

[52] P. G. de Jong, M. Coppens, and S. Middeldorp, "Duration of anticoagulant therapy for venous thromboembolism: balancing benefits and harms on the long term," British Journal of Haematology, vol. 158, no. 4, pp. 433-441, 2012.

[53] H. Gombotz and H. Knotzer, "Preoperative identification of patients with increased risk for perioperative bleeding," Current Opinion in Anaesthesiology, vol. 26, no. 1, pp. 82-90, 2013.

[54] R. Pisters, D. A. Lane, R. Nieuwlaat, C. B. De Vos, H. J. G. M. Crijns, and G. Y. H. Lip, "A novel user-friendly score (HASBLED) to assess 1-year risk of major bleeding in patients with atrial fibrillation: the euro heart survey," Chest, vol. 138, no. 5, pp. 1093-1100, 2010.

[55] M. C. Fang, A. S. Go, Y. Chang et al., "A new risk scheme to predict warfarin-associated hemorrhage: the ATRIA (Anticoagulation and Risk Factors in Atrial Fibrillation) Study," Journal of the American College of Cardiology, vol. 58, no. 4, pp. 395-401, 2011.

[56] B. F. Gage, Y. Yan, P. E. Milligan et al., "Clinical classification schemes for predicting hemorrhage: results from the National Registry of Atrial Fibrillation (NRAF)," The American Heart Journal, vol. 151, no. 3, pp. 713-719, 2006.
[57] S. Apostolakis, D. A. Lane, Y. Guo, H. Buller, and G. Y. H. Lip, "Performance of the HEMORR 2HAGES, ATRIA, and HASBLED bleeding risk-prediction scores in patients with atrial fibrillation undergoing anticoagulation: the AMADEUS (Evaluating the use of SR34006 compared to warfarin or acenocoumarol in patients with atrial fibrillation) study," Journal of the American College of Cardiology, vol. 60, no. 9, pp. 861-867, 2012.

[58] S. Apostolakis, D. A. Lane, Y. Guo, H. Buller, and G. Y. H. Lip, "Performance of the HEMORR2HAGES, ATRIA, and HASBLED bleeding risk-prediction scores in nonwarfarin anticoagulated atrial fibrillation patients," Journal of the American College of Cardiology, vol. 61, no. 3, pp. 386-387, 2013.

[59] J. A. Nieto, R. Solano, N. Trapero Iglesias et al., "Validation of a score for predicting fatal bleeding in patients receiving anticoagulation for venous thromboembolism," Thrombosis Research, vol. 132, pp. 175-179, 2013.

[60] J. D. Douketis, A. C. Spyropoulos, F. A. Spencer et al., "Perioperative management of antithrombotic therapy: antithrombotic Therapy and Prevention of Thrombosis, 9th ed: American College of Chest Physicians Evidence-Based Clinical Practice Guidelines," Chest, vol. 141, pp. e326S-e350S, 2012.

[61] A. Vuylsteke, C. Pagel, C. Gerrard et al., "The Papworth Bleeding Risk Score: a stratification scheme for identifying cardiac surgery patients at risk of excessive early postoperative bleeding," European Journal of Cardio-thoracic Surgery, vol. 39, no. 6, pp. 924-930, 2011.

[62] A. C. Spyropoulos and J. D. Douketis, "How I treat anticoagulated patients undergoing an elective procedure or surgery," Blood, vol. 120, no. 15, pp. 2954-2962, 2012.

[63] H. Heidbuchel, P. Verhamme, M. Alings et al., "European Heart Rhythm Association Practical Guide on the use of new oral anticoagulants in patients with non-valvular atrial fibrillation. Europace: European pacing, arrhythmias, and cardiac electrophysiology," Europace, vol. 15, pp. 625-651, 2013.

[64] A. Liew and J. Douketis, "Perioperative management of patients who are receiving a novel oral anticoagulant," Internal and Emergency Medicine, vol. 8, pp. 477-484, 2013.

[65] J. D. Douketis, "Perioperative anticoagulation management in patients who are receiving oral anticoagulant therapy: a practical guide for clinicians," Thrombosis Research, vol. 108, no. 1, pp. 3-13, 2002.

[66] J. D. Douketis, P. B. Berger, A. S. Dunn et al., “The perioperative management of antithrombotic therapy: American College of Chest Physicians evidence-based clinical practice guidelines (8th edition)," Chest, vol. 133, no. 6, pp. 299S-339S, 2008.

[67] M. Fujita, A. Shiotani, T. Murao et al., "Safety of gastrointestinal endoscopic biopsy in patients taking antithrombotics," Digestive Endoscopy, 2014.

[68] J. I. Weitz, D. J. Quinlan, and J. W. Eikelboom, "Periprocedural management and approach to bleeding in patients taking dabigatran," Circulation, vol. 126, no. 20, pp. 2428-2432, 2012.

[69] D. J. Greenblatt, "Elimination half-life of drugs: value and limitations," Annual Review of Medicine, vol. 36, pp. 421-427, 1985.

[70] J. Graff and S. Harder, "Anticoagulant therapy with the oral direct factor Xa inhibitors rivaroxaban, apixaban and edoxaban and the thrombin inhibitor dabigatran etexilate in patients with hepatic impairment," Clinical Pharmacokinetics, vol. 52, no. 4, pp. 243-254, 2013.

[71] D. Siegal, J. Yudin, S. Kaatz, J. D. Douketis, W. Lim, and A. C. Spyropoulos, "Periprocedural heparin bridging in patients 
receiving vitamin $\mathrm{K}$ antagonists: systematic review and metaanalysis of bleeding and thromboembolic rates," Circulation, vol. 126, no. 13, pp. 1630-1639, 2012.

[72] L. Feng, Y. Li, J. Li, and B. Yu, "Oral anticoagulation continuation compared with heparin bridging therapy among high risk patients undergoing implantation of cardiac rhythm devices: a meta-analysis," Thrombosis \& Haemostasis, vol. 108, no. 6, pp. 1124-1131, 2012.

[73] H. Omran, R. Bauersachs, S. Rubenacker, F. Goss, and C. Hammerstingl, "The HAS-BLED score predicts bleedings during bridging of chronic oral anticoagulation. Results from the national multicentre BNK Online bRiDging REgistRy (BORDER)," Thrombosis and Haemostasis, vol. 108, pp. 65-73, 2012.

[74] A. C. Spyropoulos, J. D. Douketis, G. Gerotziafas, S. Kaatz, T. L. Ortel, and S. Schulman, "Periprocedural antithrombotic and bridging therapy: recommendations for standardized reporting in patients with arterial indications for chronic oral anticoagulant therapy," Journal of Thrombosis and Haemostasis, vol. 10, no. 4, pp. 692-694, 2012.

[75] S. Schulman and C. Kearon, "Definition of major bleeding in clinical investigations of antihemostatic medicinal products in non-surgical patients," Journal of Thrombosis and Haemostasis, vol. 3, no. 4, pp. 692-694, 2005.

[76] T. Nascimento, D. H. Birnie, J. S. Healey et al., "Managing novel oral anticoagulants in patients with atrial fibrillation undergoing device surgery: Canadian survey," Canadian Journal of Cardiology, vol. 30, pp. 231-236, 2014.

[77] J. P. Patel and R. Arya, "The current status of bridging anticoagulation," British Journal of Haematology, vol. 164, no. 5, pp. 619-629, 2014.

[78] H. T. Benzon, M. J. Avram, D. Green, and R. O. Bonow, "New oral anticoagulants and regional anaesthesia," British Journal of Anaesthesia, vol. 111, supplement 1, pp. i96-i113, 2013.

[79] J. V. Llau and R. Ferrandis, "New anticoagulants and regional anesthesia," Current Opinion in Anaesthesiology, vol. 22, no. 5, pp. 661-666, 2009.

[80] W. Gogarten, E. Vandermeulen, H. van Aken, S. Kozek, J. V. Llau, and C. M. Samama, "Regional anaesthesia and antithrombotic agents: recommendations of the European Society of Anaesthesiology," European Journal of Anaesthesiology, vol. 27, no. 12, pp. 999-1015, 2010.

[81] T. T. Horlocker, D. J. Wedel, H. Benzon et al., "Regional anesthesia in the anticoagulated patient: defining the risks (the second ASRA Consensus Conference on Neuraxial Anesthesia and Anticoagulation)," Regional Anesthesia and Pain Medicine, vol. 28, no. 3, pp. 172-197, 2003.

[82] D. Lakkireddy, Y. M. Reddy, L. Di Biase et al., "Feasibility and safety of uninterrupted rivaroxaban for periprocedural anticoagulation in patients undergoing radiofrequency ablation for atrial fibrillation: results from a multicenter prospective registry," Journal of the American College of Cardiology, vol. 63, no. 10, pp. 982-988, 2014.

[83] D. Lakkireddy, Y. M. Reddy, L. di Biase et al., "Feasibility and safety of dabigatran versus warfarin for periprocedural anticoagulation in patients undergoing radiofrequency ablation for atrial fibrillation: results from a multicenter prospective registry," Journal of the American College of Cardiology, vol. 59, no. 13, pp. 1168-1174, 2012.

[84] J. Kim, F. She, K. Jongnarangsin et al., "Dabigatran vs warfarin for radiofrequency catheter ablation of atrial fibrillation," Heart Rhythm, vol. 10, no. 4, pp. 483-489, 2013.
[85] H. Yamaji, T. Murakami, K. Hina et al., "Usefulness of dabigatran etexilate as periprocedural anticoagulation therapy for atrial fibrillation ablation," Clinical Drug Investigation, vol. 33, no. 6, pp. 409-418, 2013.

[86] T. Nin, A. Sairaku, Y. Yoshida et al., "A randomized controlled trial of dabigatran versus warfarin for periablation anticoagulation in patients undergoing ablation of atrial fibrillation," PACE_Pacing and Clinical Electrophysiology, vol. 36, no. 2, pp. 172-179, 2013.

[87] R. A. Winkle, R. H. Mead, G. Engel, M. H. Kong, and R. A. Patrawala, "The use of dabigatran immediately after atrial fibrillation ablation," Journal of Cardiovascular Electrophysiology, vol. 23, no. 3, pp. 264-268, 2012.

[88] G. Pernod, P. Albaladejo, A. Godier et al., "Management of major bleeding complications and emergency surgery in patients on long-term treatment with direct oral anticoagulants, thrombin or factor-Xa inhibitors: proposals of the working group on perioperative haemostasis (GIHP) - March 2013," Archives of Cardiovascular Diseases, vol. 106, no. 6-7, pp. 382393, 2013

[89] J. Van Ryn, J. Stangier, S. Haertter et al., "Dabigatran etexilate-a novel, reversible, oral direct thrombin inhibitor: interpretation of coagulation assays and reversal of anticoagulant activity," Thrombosis and Haemostasis, vol. 103, no. 6, pp. 1116-1127, 2010.

[90] T. E. Warkentin, P. Margetts, S. J. Connolly, A. Lamy, C. Ricci, and J. W. Eikelboom, "Recombinant factor VIIa (rFVIIa) and hemodialysis to manage massive dabigatran-associated postcardiac surgery bleeding," Blood, vol. 119, no. 9, pp. 2172-2174, 2012.

[91] M. R. Wanek, E. T. Horn, S. Elapavaluru, S. C. Baroody, and G. Sokos, "Safe use of hemodialysis for dabigatran removal before cardiac surgery," Annals of Pharmacotherapy, vol. 46, article e21, no. $9,2012$.

[92] D. Khadzhynov, F. Wagner, S. Formella et al., "Effective elimination of dabigatran by haemodialysis: a phase I single-centre study in patients with end-stage renal disease," Thrombosis \& Haemostasis, vol. 109, no. 4, pp. 596-605, 2013.

[93] S. A. Kozek-Langenecker, "Perioperative management issues of direct oral anticoagulants," Seminars in Hematology, vol. 51, pp. 112-120, 2014.

[94] A. Majeed, H. G. Hwang, S. J. Connolly et al., "Management and outcomes of major bleeding during treatment with dabigatran or warfarin," Circulation, vol. 128, pp. 2325-2332, 2013.

[95] G. Lu, F. R. Deguzman, S. J. Hollenbach et al., "A specific antidote for reversal of anticoagulation by direct and indirect inhibitors of coagulation factor Xa," Nature Medicine, vol. 19, no. 4, pp. 446-451, 2013.

[96] O. Grottke, J. van Ryn, H. M. Spronk, and R. Rossaint, "Prothrombin complex concentrates and a specific antidote to dabigatran are effective ex-vivo in reversing the effects of dabigatran in an anticoagulation/liver trauma experimental model," Critical Care, vol. 18, no. 2, article R27, 2014.

[97] A. Majeed and S. Schulman, "Bleeding and antidotes in new oral anticoagulants," Best Practice and Research: Clinical Haematology, vol. 26, no. 2, pp. 191-202, 2013.

[98] T. Baglin, A. Hillarp, A. Tripodi, I. Elalamy, H. Buller, and W. Ageno, "Measuring oral direct inhibitors of thrombin and factor Xa: a recommendation from the Subcommittee on Control of Anticoagulation of the Scientific and Standardization Committee of the International Society on Thrombosis and Haemostasis," Journal of Thrombosis and Haemostasis, vol. 11, no. 4, pp. 756-760, 2013. 
[99] P. Gallego, S. Apostolakis, and G. Y. H. Lip, "Bridging evidencebased practice and practice-based evidence in periprocedural anticoagulation," Circulation, vol. 126, no. 13, pp. 1573-1576, 2012.

[100] European medicine Agency-Pradaxa-H-C-829-X-13: EPARAssessment Report-Extension, 2011, http://www.ema.europa .eu/docs/en_GB/document_library/EPAR_-_Assessment_Report__Variation/human/000829/WC500110875.pdf.

[101] J. Douxfils, F. Mullier, S. Robert, C. Chatelain, B. Chatelain, and J. Dogné, "Impact of dabigatran on a large panel of routine or specific coagulation assays: Laboratory recommendations for monitoring of dabigatran etexilate," Thrombosis and Haemostasis, vol. 107, no. 5, pp. 985-997, 2012.

[102] J. P. Antovic, M. Skeppholm, J. Eintrei et al., "Evaluation of coagulation assays versus LC-MS/MS for determinations of dabigatran concentrations in plasma," European Journal of Clinical Pharmacology, vol. 69, no. 11, pp. 1875-1881, 2013.

[103] E. M. Hawes, A. M. Deal, D. Funk-Adcock et al., "Performance of coagulation tests in patients on therapeutic doses of dabigatran: a cross-sectional pharmacodynamic study based on peak and trough plasma levels," Journal of Thrombosis and Haemostasis, vol. 11, no. 8, pp. 1493-1502, 2013.

[104] J. Douxfils, J. M. Dogné, F. Mullier et al., "Comparison of calibrated dilute thrombin time and aPTT tests with LC-MS/MS for the therapeutic monitoring of patients treated with dabigatran etexilate," Thrombosis \& Haemostasis, vol. 110, no. 3, pp. 543-549, 2013.

[105] J. Douxfils, A. Tamigniau, B. Chatelain et al., "Comparison of calibrated chromogenic anti-Xa assay and PT tests with LCMS/MS for the therapeutic monitoring of patients treated with rivaroxaban," Thrombosis and Haemostasis, vol. 110, pp. 723-731, 2013.

[106] J. Douxfils, C. Chatelain, B. Chatelain, J. Dogné, and F. Mullier, "Impact of apixaban on routine and specific coagulation assays: a practical laboratory guide," Thrombosis and Haemostasis, vol. 110, no. 2, pp. 283-294, 2013.

[107] C. Frost, J. Wang, S. Nepal et al., "Apixaban, an oral, direct factor Xa inhibitor: single dose safety, pharmacokinetics, pharmacodynamics and food effect in healthy subjects," The British Journal of Clinical Pharmacology, vol. 75, no. 2, pp. 476-487, 2013.

[108] I. Gouin-Thibault, C. Flaujac, X. Delavenne et al., "Assessment of apixaban plasma levels by laboratory tests: suitability of three anti-Xa assays. A multicentre French GEHT study," Thrombosis and Haemostasis, vol. 111, no. 2, pp. 240-248, 2014.

[109] S. J. Francart, E. M. Hawes, A. M. Deal et al., "Performance of coagulation tests in patients on therapeutic doses of rivaroxaban. A cross-sectional pharmacodynamic study based on peak and trough plasma levels," Thrombosis and Haemostasis, vol. 111, no. 6, pp. 1133-1140, 2013.

[110] A. Tamigniau, J. Douxfils, and J. B. Nicolas, "Why, when and how to monitor new oral anticoagulants," Revue Médicale Suisse, vol. 10, pp. 326-333, 2014.

[111] H. Calkins, K. H. Kuck, R. Cappato et al., "2012 HRS/EHRA/ ECAS expert consensus statement on catheter and surgical ablation of atrial fibrillation: recommendations for patient selection, procedural techniques, patient management and follow-up, definitions, endpoints, and research trial design," Journal of Interventional Cardiac Electrophysiology, vol. 33, no. 2, pp. 171257, 2012.
[112] D. R. Jobes, N. Ellison, and F. W. Campbell, "Limit(ation)s for ACT (I)," Anesthesia and Analgesia, vol. 69, no. 1, pp. 142-144, 1989.

[113] B. Jude, D. Lasne, C. Mouton, and P. de Moerloose, "Monitoring of heparin therapy during extracorporeal bypass: what are the remaining questions?" Annales Francaises d'Anesthesie et de Reanimation, vol. 23, no. 6, pp. 589-596, 2004.

[114] H. M. Hussein, A. L. Georgiadis, and A. I. Qureshi, "Point-ofcare testing for anticoagulation monitoring in neuroendovascular procedures," The American Journal of Neuroradiology, vol. 33, no. 7, pp. 1211-1220, 2012.

[115] E. B. Saad, I. P. Costa, R. E. da Costa et al., "Safety of ablation for atrial fibrillation with therapeutic INR: comparison with transition to low-molecular-weight heparin," Arquivos Brasileiros de Cardiologia, vol. 97, no. 4, pp. 289-296, 2011.

[116] R. Cappato, H. Calkins, S. Chen et al., "Updated worldwide survey on the methods, efficacy, and safety of catheter ablation for human atrial fibrillation," Circulation: Arrhythmia and Electrophysiology, vol. 3, no. 1, pp. 32-38, 2010.

[117] R. Cappato, H. Calkins, S.-A. Chen et al., "Worldwide survey on the methods, efficacy, and safety of catheter ablation for human atrial fibrillation," Circulation, vol. 111, no. 9, pp. 1100-1105, 2005.

[118] A. C. Spyropoulos and A. G. G. Turpie, "Perioperative bridging interruption with heparin for the patient receiving long-term anticoagulation," Current Opinion in Pulmonary Medicine, vol. 11, no. 5, pp. 373-379, 2005.

[119] S. Kaatz, J. D. Douketis, H. Zhou, B. F. Gage, and R. H. White, "Risk of stroke after surgery in patients with and without chronic atrial fibrillation," Journal of Thrombosis and Haemostasis, vol. 8, no. 5, pp. 884-890, 2010.

[120] A. J. Tafur, R. McBane, W. E. Wysokinski et al., "Predictors of major bleeding in peri-procedural anticoagulation management," Journal of Thrombosis and Haemostasis, vol. 10, no. 2, pp. 261-267, 2012.

[121] A. G. Turpie, R. Kreutz, J. Llau, B. Norrving, and S. Haas, "Management consensus guidance for the use of rivaroxaban-an oral, direct factor Xa inhibitor," Thrombosis \& Haemostasis, vol. 108, no. 5, pp. 876-886, 2012.

[122] M. V. Huisman, G. Y. H. Lip, H. Diener, M. Brueckmann, J. van Ryn, and A. Clemens, "Dabigatran etexilate for stroke prevention in patients with atrial fibrillation: resolving uncertainties in routine practice," Thrombosis and Haemostasis, vol. 107, no. 5, pp. 838-847, 2012.

[123] E. A. Nutescu, S. A. Spinler, A. Wittkowsky, and W. E. Dager, "Low-molecular-weight heparins in renal impairment and obesity: available evidence and clinical practice recommendations across medical and surgical settings," Annals of Pharmacotherapy, vol. 43, no. 6, pp. 1064-1083, 2009. 


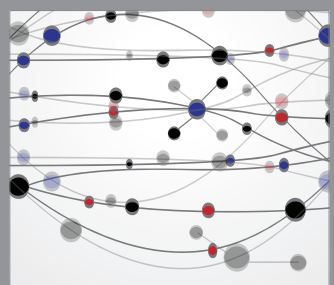

The Scientific World Journal
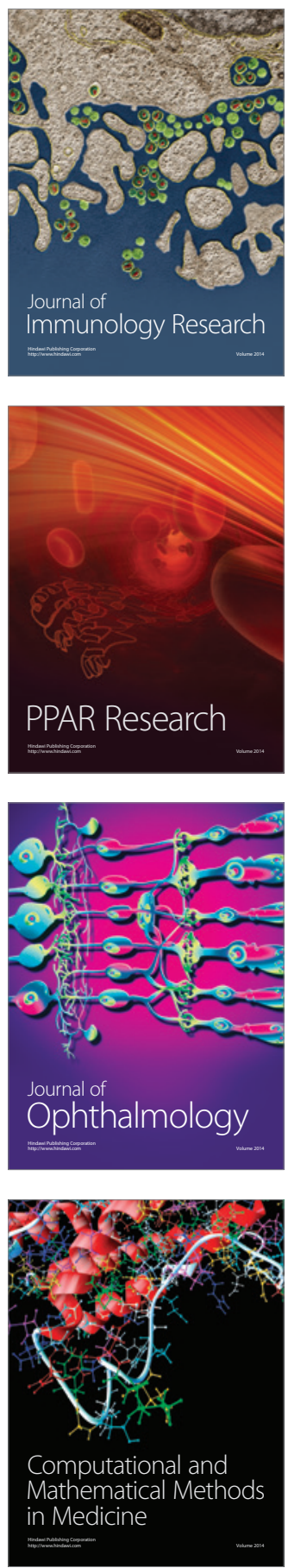

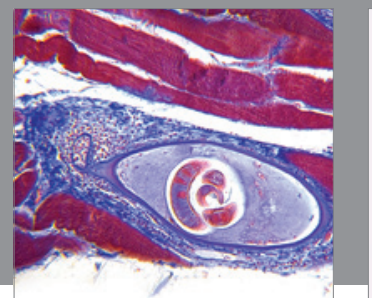

Gastroenterology

Research and Practice
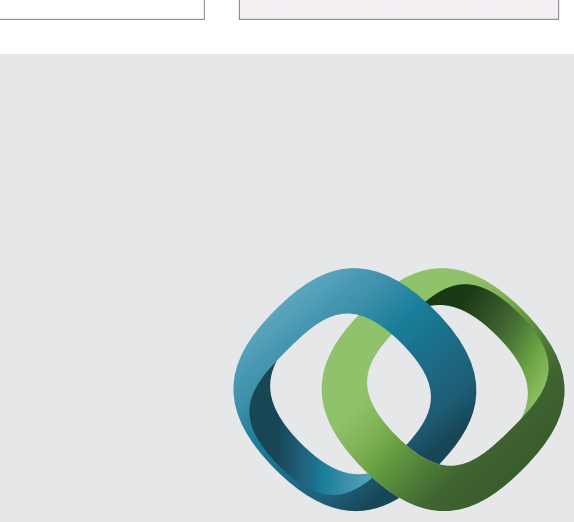

\section{Hindawi}

Submit your manuscripts at

http://www.hindawi.com
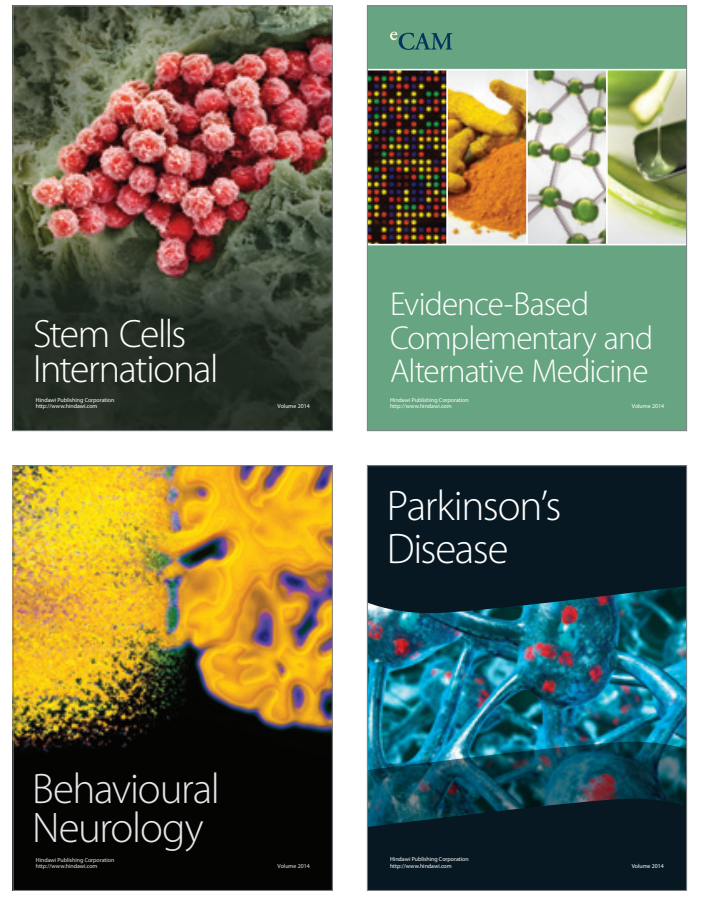
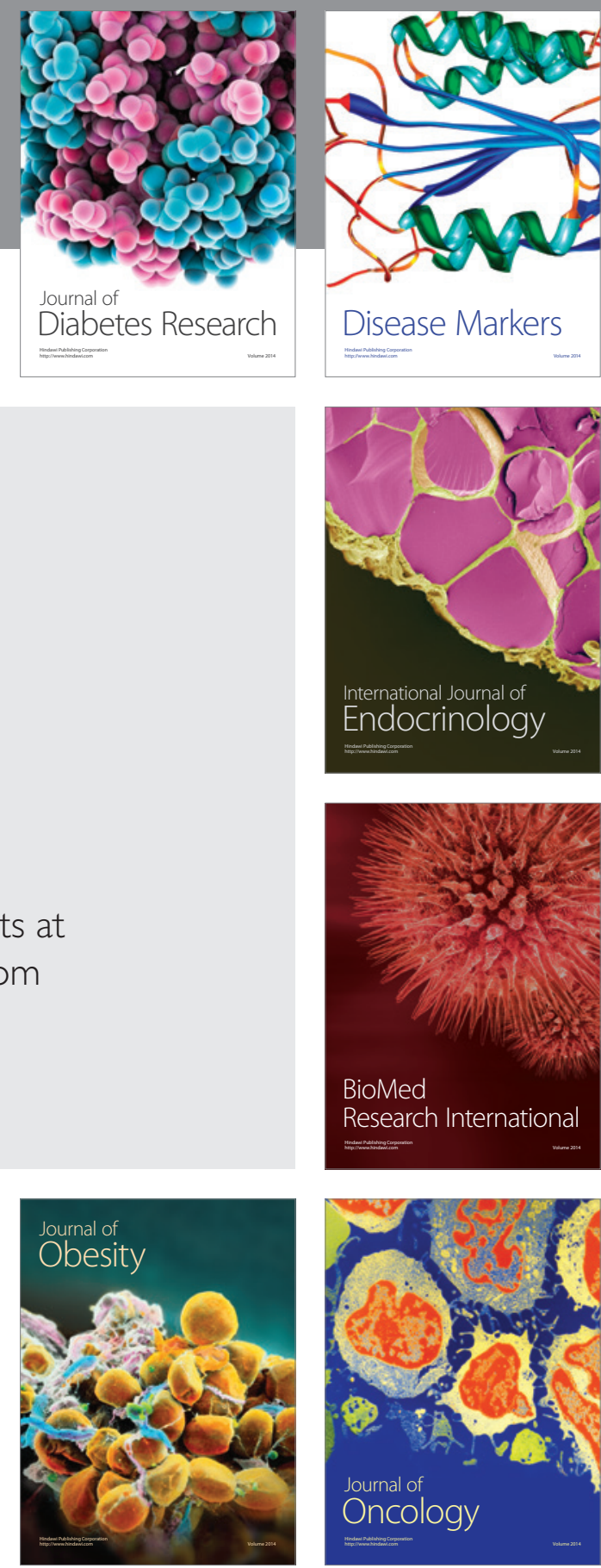

Disease Markers
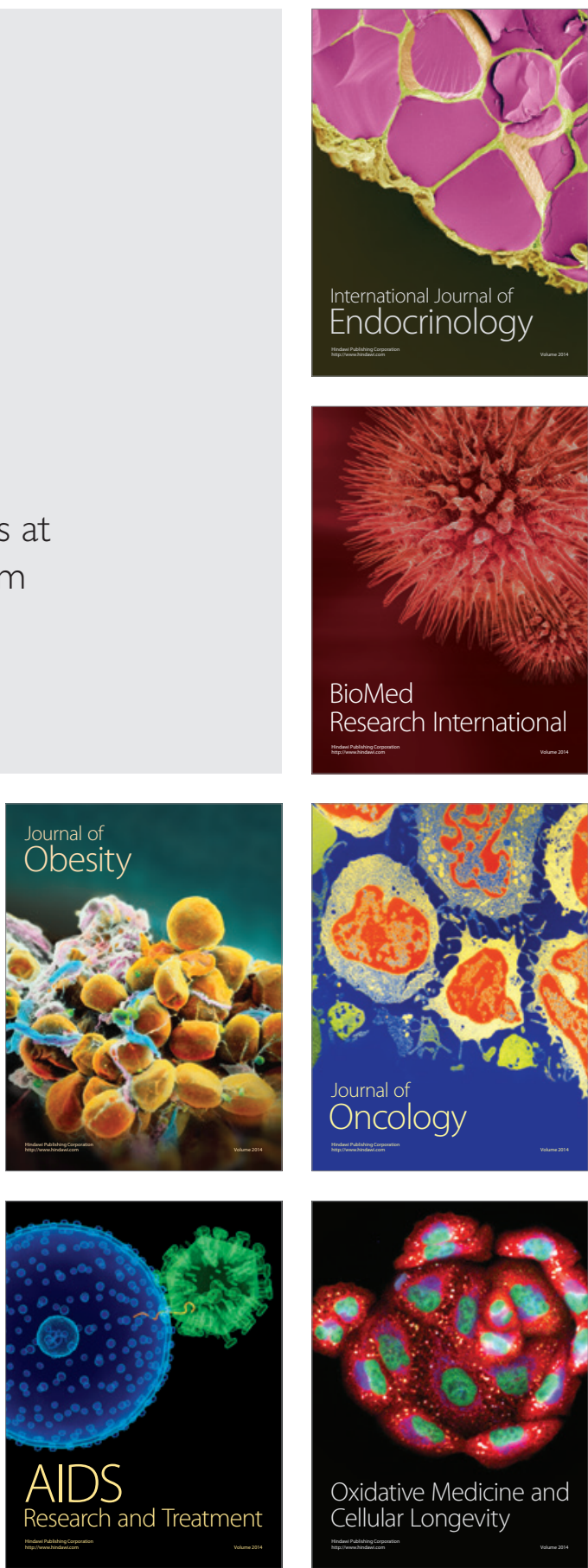